Article

\title{
Investigation of the Kinetic Regularities of the Process of Biodegradation of Betaine Surfactant by Bacteria of the Genus Pseudomonas
}

\author{
Anastasia S. Burlachenko ${ }^{1}$, Olesya V. Salishcheva ${ }^{2, *}{ }^{\mathbb{D}}$, Lyubov S. Dyshlyuk ${ }^{1}$ and Alexander Y. Prosekov ${ }^{1}$ (i) \\ 1 Department of Bionanotechnology, Kemerovo State University, 650000 Kemerovo, Russia; \\ nastya_sergeevna99@mail.ru (A.S.B.); soldatovals1984@mail.ru (L.S.D.); rector@kemsu.ru (A.Y.P.) \\ 2 Department of General and Inorganic Chemistry, Kemerovo State University, 650000 Kemerovo, Russia \\ * Correspondence: salishchevaov@mail.ru
}

Citation: Burlachenko, A.S.; Salishcheva, O.V.; Dyshlyuk, L.S.; Prosekov, A.Y. Investigation of the Kinetic Regularities of the Process of Biodegradation of Betaine Surfactant by Bacteria of the Genus Pseudomonas. Appl. Sci. 2021, 11, 8939. https:// doi.org/10.3390/app11198939

Received: 25 August 2021

Accepted: 22 September 2021

Published: 25 September 2021

Publisher's Note: MDPI stays neutral with regard to jurisdictional claims in published maps and institutional affiliations.

Copyright: (c) 2021 by the authors. Licensee MDPI, Basel, Switzerland. This article is an open access article distributed under the terms and conditions of the Creative Commons Attribution (CC BY) license (https:// creativecommons.org/licenses/by/ $4.0 /)$.

\begin{abstract}
Surfactants are extremely common organic compounds that enter the environment in large quantities in the form of household and industrial wastewater. The toxicity of surfactants for biological systems, the high concentration of substances and the duration of the bioremediation process of polluted ecosystems requires improving the biotechnology of microbial wastewater treatment for surfactants. The purpose of this work is to study the kinetic laws of the reaction of the biological decomposition of betaine surfactants. Pseudomonas bacteria were used as bio-destructors of the surfactants. Kinetic data were obtained to create the possibility of further optimization of research on the biodegradation of toxic organic substances. The strains that were promising destructors of cocamidopropylbetaine were selected. The toxicity of high concentrations of surfactants in relation to microorganisms of the genus Pseudomonas was proven. Safe values of the surfactant concentration for conducting biodegradation tests were found. A kinetic model of the biodestructive process was constructed. It proves that the processes of biodegradation are described by a kinetic equation of the first order. With the derived equation, it is possible to determine the time interval of biodegradation of cocamidopropylbetaine to the specified values by means of mathematical calculations.
\end{abstract}

Keywords: kinetics of biodestruction; cocamidopropylbetaine; surfactants bioremediation; surfactantdegrading bacteria of the genus Pseudomonas; aerobic biodegradation; biological wastewater treatment

\section{Introduction}

Currently, there is an acute problem with the utilization of synthetic organic surfactants that interfere with the normal functioning of the ecosystem. Surfactants are organic substances that contain hydrophilic and hydrophobic groups. They are divided into ionic and non-ionic, depending on their ability to dissociate. Ionic surfactants include anionic, cationic, amphoteric and zwitterionic surfactants in accordance with the negative, positive and neutral charge of the hydrophilic group [1].

One of the most utilized groups of surfactants is betaine surfactants (zwitterionic). They are widely used as components of industrial, household and cosmetic products due to their surface-active properties and resistance to oxidation. They stabilize the interfacial surface, contributing to the formation of aggregative unstable systems, for example, foams in surfactant compositions [2]. Some types of betaine surfactants are used in oil fields to achieve hydraulic fracturing, as additives to demulsifiers, to increase oil recovery [3]. Due to its antistatic properties, as well as the ability to actively foam and increase the viscosity of solutions, the zwitterion alkylamidobetaine surfactant cocamidopropylbetaine (CAPB) is widely used on the market [4,5].

Scientific sources have data on the toxicity of betaine surfactants, in particular cocamidopropylbetaine. It is proved that surfactant interferes with the phospholipid bilayer of the cell and binds to membrane proteins, thereby disrupting their functions and causing 
lysis of living cells. Once inside the cell, surfactant affects the organization of thylakoids and the synthesis of chlorophyll $[6,7]$. The ability of CAPB to manifest powerful antiseptic properties was proved in $[8,9]$. In addition, dropping off surfactants to biological treatment facilities can cause serious problems in the operation of activated sludge, in particular, the inhibition of protein structures of microorganisms $[2,10,11]$. Surfactants also cause increased foaming and are adsorbed on bacterial cells, which negatively affects the biodegradability of wastewater components $[12,13]$.

To date, it has been possible to identify fragments that are formed as a result of the destruction of cocamidopropylbetaine under the influence of physic and chemical factors. The author of [14] found that the destruction of this surfactant leads to the formation of $\mathrm{N}, \mathrm{N}$-dimethylglycine, which subsequently decomposes into acetic acid anion, ammonia, nitrogen oxides, carbon dioxide and $\mathrm{N}$-allylammonium forms. Next, the $\mathrm{N}$-allylammonium derivatives decompose into an acyl ion or an immonium ion, which is a very toxic cation (Figure 1). It was proved that the safest and most effective method of surfactant utilization is the biological method, since in the process of enzymatic decomposition, the final products do not pose a danger to the environment $[15,16]$.

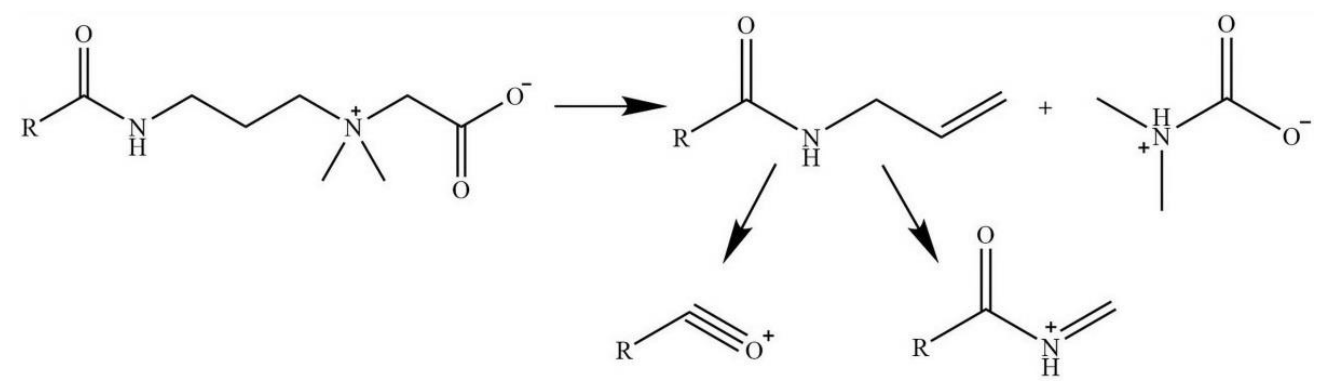

Figure 1. Destruction of CAPB under the influence of physical and chemical factors.

The decomposition of betaine surfactants includes the decomposition of the hydrophobic chain of the fatty acid and the biodegradation of the hydrophilic part. The fat chain undergoes destruction by the mechanisms of $\omega$-oxidation and $\beta$-oxidation. After $\omega$-oxidation, a hydrophilic molecule with a low molecular weight remains. The process of $\beta$-oxidation of alkylbetaine is accompanied by further decomposition to methane, carbon dioxide and ammonia [13].

It is known that strains of microorganisms of the genus Pseudomonas are destructors of a wide range of hydrocarbons $[16,17]$. This is due to the peculiarities of the peripheral metabolism of bacteria and the peculiarities of the structure of the cell wall $[4,18]$. Strains of this genus are present in large quantities in wastewater, in sewage treatment plants and in soil. Due to the fact that they are constantly exposed to high concentrations of toxic compounds, through natural selection they have acquired a high biodegradative potential. On account of these features, representatives of this genus are promising objects of biotechnological research.

To optimize the work of microbiological objects in order to implement surfactant biodegradation, it is necessary to understand the kinetic model of the process, which will theoretically determine the end time of the decomposition of the substance, as well as quickly select the necessary parameters for conducting research in which new organic compounds and other strains of microorganisms will be used as objects [19]. There are many studies on the processes of biodegradation of polymer materials [19-22], but the question of the features of the bacterial destruction of synthetic surfactants requires a fundamental approach and versatile research.

Due to the fact that the field of application of betaine surfactants is quite extensive and studies on their biodestruction are fragmentary, the kinetic model of the biodestruction process is considered specifically for this group of surfactants based on the example of cocamidopropylbetaine. 
The purpose of the research is to study the rate of the process of biodegradation of cocamidopropylbetaine by bacteria of the genus Pseudomonas and determine the main kinetic parameters of the reaction of the biological decomposition of the surfactant.

\section{Materials and Methods}

The objects of the study are destructor strains acquired from the Russian National Collection of Industrial Microorganisms National Bioresource Center (RNCIM BRC) SRC "Kurchatov Institute"-GosNIIGenetika: Pseudomonas chlororaphis subsp aurantiaca (B-3419) 128, Pseudomonas oryzihabitans (B-12467) Tik3, Pseudomonas pseudoalcaligenes (B-6783) VSB10, Pseudomonas balearica (B-12843) 1-2, Pseudomonas mendocina (B-5330), and amphoteric surfactant cocamidopropylbetaine CAPB $(30 \%)$, made in Italy.

To determine the concentration that inhibits the growth of microorganisms, a macromethod was used. For this purpose, 8 solutions of surfactants were prepared. The concentration of each subsequent solution was half the previous one. The initial surfactant concentration was $0.7296 \mathrm{~mol} / \mathrm{dm}^{3}$. Next, a suspension based on a saline solution $(0.9 \% \mathrm{NaCl}$ solution) with a final concentration of $10^{7}-10^{8} \mathrm{CFU} / \mathrm{mL}$ was prepared for each microorganism. The number of colonies was determined using a DEN-1 densitometer by the turbidity of cell suspensions within the value of $0.5 \mathrm{McF}$ arland units $\left(1 \times 10^{8} \mathrm{CFU} / \mathrm{mL}\right)$. A suspension of the destructor strain of $1 \mathrm{~cm}^{3}$ was added to each test tube. After $24 \mathrm{~h}$, light scattering was measured at a wavelength of $980 \mathrm{~nm}$ using a UV 1800 spectrophotometer (Shimadzu, Kyoto, Japan). The minimum inhibitory concentration (MIC) corresponds to the minimum content of surfactants in the solution, at which the growth of biomass is inhibited.

With the aim of obtaining experimental data to construct a kinetic model of the process of biodegradation of the surfactant, glass flasks were prepared with a volume of $250 \mathrm{~cm}^{3}$ sterile solutions of cocamidopropylbetaine in three concentrations $\left(C_{1}=22.8 \mathrm{mmol} / \mathrm{dm}^{3}\right.$, $C_{2}=$ of $11.4 \mathrm{mmol} / \mathrm{dm}^{3}, C_{3}=5.7 \mathrm{mmol} / \mathrm{dm}^{3}$ ) for each of the five destructor strains. Then, suspensions of strains in the volume of $1 \mathrm{~cm}^{3}$ were transplanted into glass flasks under sterile conditions.

The microorganisms were cultured at $30{ }^{\circ} \mathrm{C}$ in the LSI-3016A/LSI-3016R shaker incubator (Daihan Labtech, Namyangju-si, South Korea).

The degree of biodegradation was determined by measuring the residual concentration of surfactants in the solution. For this purpose, samples of each of the solutions were taken daily in a volume of $5 \mathrm{~cm}^{3}$. The samples were cleaned of bacterial cells by centrifugation until a transparent solution was obtained. In parallel, a solution of the black $\mathrm{T}$ eriochrome indicator and a solution of a sodium-phosphate buffer $(\mathrm{pH}=6.86)$ were prepared in accordance with the procedure [23]. Solutions of the following composition were prepared for measurements:

(1) For solutions with a surfactant concentration $C_{1}=22.8 \mathrm{mmol} / \mathrm{dm}^{3}, 5.0 \mathrm{~cm}^{3}$ buffers and $1.0 \mathrm{~cm}^{3}$ indicators were added to $5 \mathrm{~cm}^{3}$ of the sample;

(2) For solutions with a surfactant concentration $C_{2}=11.4 \mathrm{mmol} / \mathrm{dm}^{3}, 5.5 \mathrm{~cm}^{3}$ buffers and $0.5 \mathrm{~cm}^{3}$ indicators were added to $5 \mathrm{~cm}^{3}$ of the sample;

(3) For solutions with a surfactant concentration $C_{3}=5.7 \mathrm{mmol} / \mathrm{dm}^{3}, 5.75 \mathrm{~cm}^{3}$ buffers and $0.25 \mathrm{~cm}^{3}$ indicators were added to $5 \mathrm{~cm}^{3}$ of the sample.

The values of the optical density of the solutions were measured with a UV 1800 spectrophotometer (Shimadzu, Kyoto, Japan) at a wavelength of $659 \mathrm{~nm}$ in a cuvette with a light-absorbing layer thickness of $1 \mathrm{~cm}$.

The reaction order and the value of the reaction rate constant were determined by graphical and analytical methods. Mathematical data processing was carried out in the Excel program. The statistical analysis data are expressed as the average value \pm standard deviation of three parallel measurements. Correlation and regression analysis as well as the evaluation of the reliability of the results were carried out using the Microsoft Excel Office 2017 package; the sample results were considered reliable at $p \leq 0.05$. 


\section{Results}

\subsection{Selecting the Working Concentration of the Surfactant}

Before setting up kinetic experiments, it was necessary to solve the problem of selecting the working concentration of the surfactant. It is known that antimicrobial activity is correlated along the "dose-effect" line. Accordingly, it would not be advisable to use the initial concentration of commercial surfactants as the working concentration. All the tested strains of microorganisms were subjected to antimicrobial screening, determining the growth of bacterial biomass in surfactant solutions of different concentrations by measuring the light-scattering intensity. On the curve of the dependence of light scattering on concentration, the minimum inhibitory concentration is determined by a characteristic bend (Figure 2).

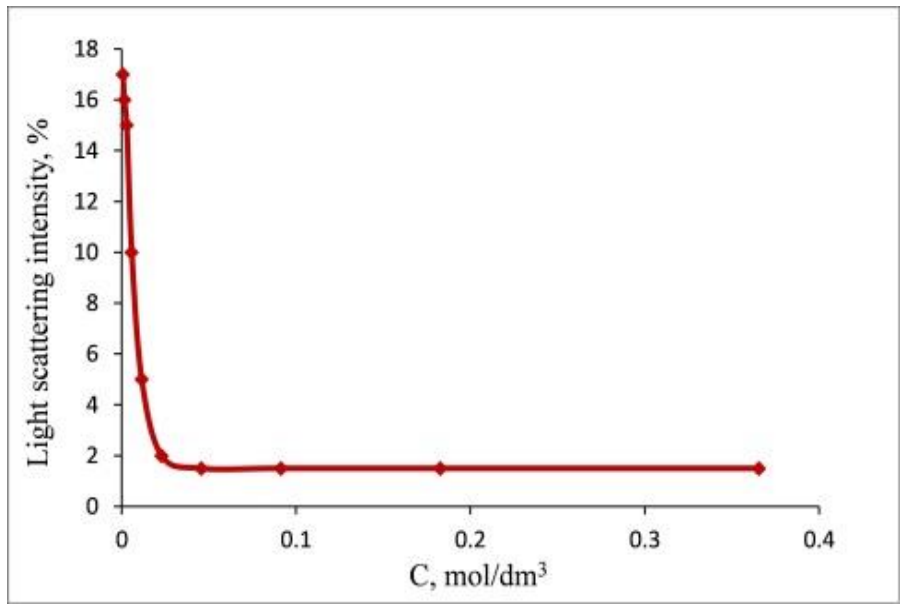

Figure 2. Dependence of the light-scattering intensity on the CAPB concentration in the solution of suspensions of the strain Pseudomonas pseudoalcaligenes (B-6783) VSB-10.

As shown in Table 1, the minimum inhibitory concentration of CAPB for all tested strains is $45.6 \mathrm{mmol} / \mathrm{dm}^{3}$.

Table 1. Inhibition of microbial growth in the presence of $\mathrm{CAPB}^{1}$.

\begin{tabular}{cccccccccc}
\hline \multirow{2}{*}{ Strain } & \multicolumn{7}{c}{ Surfactant Concentration, $\mathbf{m m o l} / \mathbf{d m}^{3}$} \\
\cline { 2 - 9 } & $\mathbf{7 2 9 . 6}$ & $\mathbf{3 6 4 . 8}$ & $\mathbf{1 8 2 . 4}$ & $\mathbf{9 1 . 2}$ & $\mathbf{4 5 . 6}$ & $\mathbf{2 2 . 8}$ & $\mathbf{1 1 . 4}$ & $\mathbf{5 . 7}$ \\
\hline $\begin{array}{c}\text { Ps. chlororaphis subsp aurantiaca } \\
\text { (B-3419) } 128\end{array}$ & - & - & - & - & - & + & + & + \\
\hline $\begin{array}{c}\text { Ps. Oryzihabitans } \\
\text { (B-12467) Tik3 }\end{array}$ & - & - & - & - & - & + & + & + \\
\hline $\begin{array}{c}\text { Ps. Pseudoalcaligenes } \\
\text { (B-6783) VSB-10 }\end{array}$ & - & - & - & - & - & + & + & + \\
\hline $\begin{array}{c}\text { Ps. Balearica } \\
\text { (B-12843) 1-2 }\end{array}$ & - & - & - & - & - & + & + & + \\
\hline $\begin{array}{c}\text { Ps. Mendocina } \\
\text { (B-5330) }\end{array}$ & - & - & - & - & - & + & + & + \\
\hline
\end{tabular}

1 "_" growth inhibition; "+" active biomass growth.

Thus, the working concentration of $C=22.8 \mathrm{mmol} / \mathrm{dm}^{3}$ was selected for further studies.

\subsection{Obtaining the Initial Experimental Data}

To derive the kinetic equation describing the process of biodegradation of surfactants, experimental data on changes in the concentration of either the starting substance or the biodegradation products during the process were necessary. To obtain the initial kinetic 
data, we tracked the dynamics of changes in the surfactant concentration. The residual concentration of CAPB was determined by the spectrophotometric method in the visible region of the spectrum, measuring the optical density of the samples in the presence of the eriochrome black $\mathrm{T}$ indicator. The kinetic curves obtained for solutions of the tested strains at the initial surfactant concentration of $\mathrm{C}_{0}=5.7 \mathrm{mmol} / \mathrm{dm}^{3}$ are shown in Figure 3 .

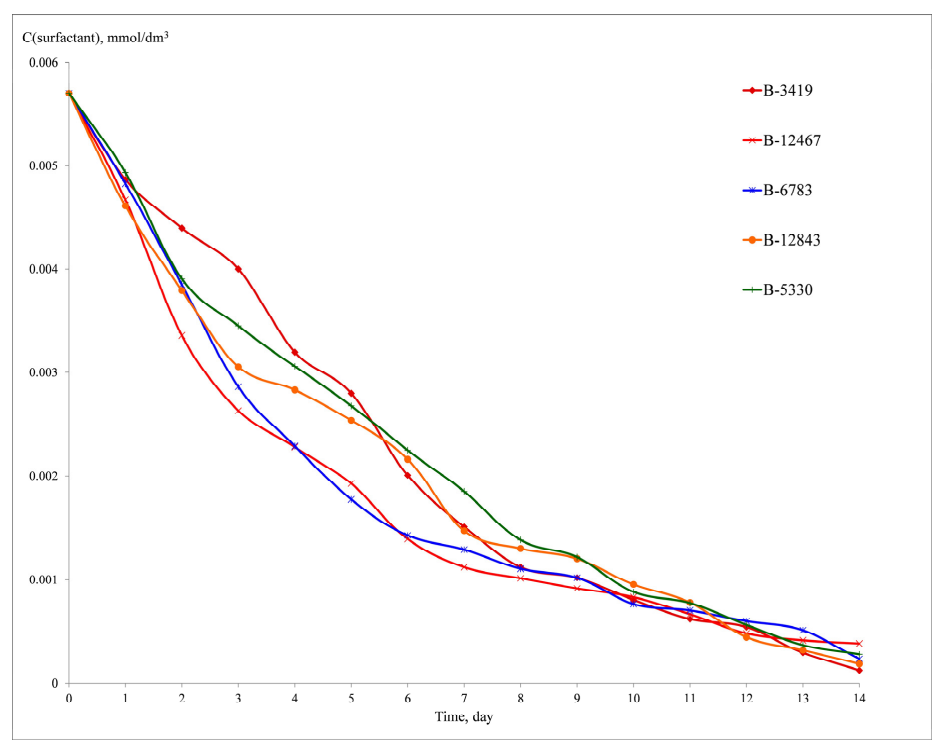

Figure 3. Dependence of CAPB concentration on the duration of biodegradation by Pseudomonas bacteria.

\subsection{Method of Initial Concentrations}

To determine the order of the reaction of biological decomposition of an organic compound, preliminary data were obtained by the method of initial concentrations. To achieve this, we prepared suspensions of microorganisms using surfactant solutions of various initial concentrations as a nutrient medium. For fourteen days, samples were taken daily and the residual concentration of surfactant was measured. Next, the biodegradation rate curves were constructed for solutions of different initial concentrations. Using the obtained curves, the values of the initial velocity were found as the angle of inclination of the tangent to point $C_{0}$ on the kinetic curve.

The dependence of the initial rate on the initial surfactant concentration of the biodegradation process of CAPB by the strain Pseudomonas pseudoalcaligenes (B-6783) VSB-10 is shown in Figure 4. Similar results were obtained for the other tested bacteria.

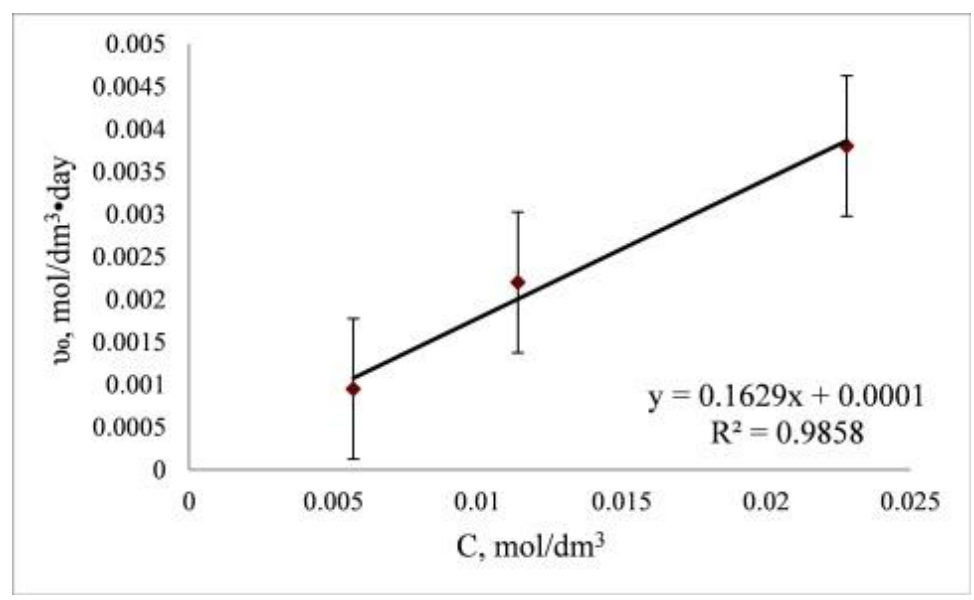

Figure 4. Linear dependence of the initial rate of the biodegradation process of CAPB by the strain Pseudomonas pseudoalcaligenes (B-6783) VSB-10 on the initial surfactant concentration. 
The results show that in this concentration range, when the surfactant concentration is doubled, the reaction rate for each of the tested strains is doubled. Taking into account that the surfactant concentration is limiting in relation to the number of bacterial cells, the results obtained (Figure 4) indicate that the process of biodegradation, regardless of the strain involved in the process, can be described by the first-order reaction equation:

$$
-\frac{d c}{d \tau}=k \times[C A P B]^{n}
$$

In Equation (1), $k$ is the reaction rate constant; [CAPB] is the surfactant concentration; and $n$ is the reaction order.

\subsection{Graphical Method to Determine the Rate Constant}

To determine the rate constant and confirm the reaction order, all subsequent experimental data were processed using kinetic equations for reactions of order 0, I, II and III using graphical and analytical methods.

For this purpose, suspensions of microorganisms were prepared using surfactant solutions of an initial concentration of $22.8 \mathrm{mmol} / \mathrm{dm}^{3}$ as a nutrient medium. Every day, for fourteen days, samples were taken and centrifuged, and the residual concentration of the surfactant was measured.

Then, using the obtained experimental values, graphs were plotted in four coordinate systems for each of the samples. The kinetic curves of the CAPB biodegradation process by the bacterium Pseudomonas pseudoalcaligenes (B-6783) VSB-10 are shown in Figure 5.

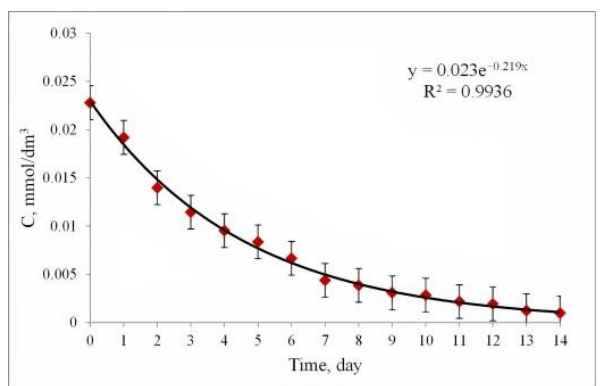

(a)

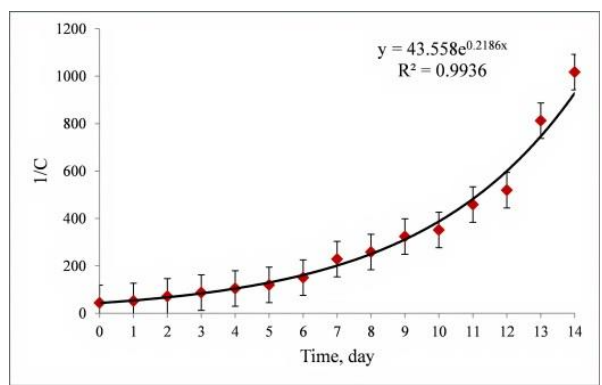

(c)

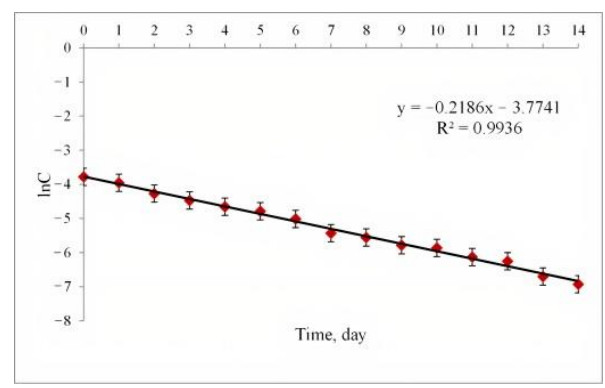

(b)

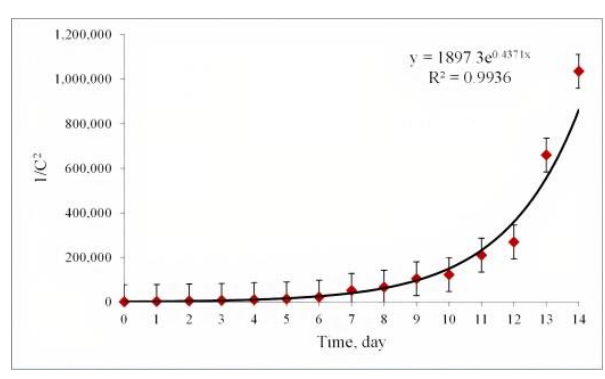

(d)

Figure 5. Kinetic curves of the CAPB biodegradation process by the strain Pseudomonas pseudoalcaligenes (B-6783) VSB-10 in four coordinate systems: (a) the coordinate system for the 0th order reaction; (b) the coordinate system for the 1st order reaction; (c) the coordinate system for the 2nd order reaction; (d) the coordinate system for the 3 rd order reaction.

A linear dependence is observed on the graph constructed in the «lnC- $\tau »$ coordinate system (Figure $5 b$ ). The graphs constructed in the coordinate systems «C- $\tau$ » (Figure $5 a)$, «1/C- $\tau »$ (Figure $5 \mathrm{c}$ ) and $« 1 / \mathrm{C}^{2}-\tau »$ (Figure $5 \mathrm{~d}$ ) are characterized by an exponential dependence. Consequently, the results obtained do not contradict the theory of the kinetics of chemical processes and the reaction of the biological decomposition of cocamidopropylbetaine can be attributed to a first-order reaction [24,25]. 
According to the equations of the lines obtained for each of the five destructor strains, the reaction rate constants were found. The velocity constants were determined as the tangent of the angle of inclination of the straight line to the abcissa axis, the value of which corresponded to the multiplier in the linear equation of the trend line, obtained by processing experimental data in the Microsoft Excel program.

\subsection{Analytical Method to Determine the Rate Constant}

In order to confirm the reliability of the results obtained, the reaction order and the value of the rate constant were determined by the analytical method, by substituting the experimentally obtained values into the equations of the reaction rate constants for the I, II and III orders. The obtained data are presented in Table 2.

Table 2. Experimental data and calculation of the rate constant of the biological decomposition of CAPB by the strain Pseudomonas pseudoalcaligenes (B-6783) VSB-10.

\begin{tabular}{ccccc}
\hline Time, Day & $\mathbf{C}, \mathbf{m o l} / \mathbf{d m}^{3}$ & $k_{1}=\frac{1}{\tau} \cdot \ln \frac{c_{0}}{c}$ & $k_{2}=\frac{1}{\tau} \cdot\left(\frac{1}{c}-\frac{1}{c_{0}}\right)$ & $k_{3}=\frac{1}{2 \tau} \cdot\left(\frac{1}{c^{2}}-\frac{1}{c_{0}^{2}}\right)$ \\
\hline 0 & 0.0228 & - & - & - \\
\hline 1 & 0.0191 & 0.172 & 8.2 & 395 \\
\hline 2 & 0.0139 & 0.244 & 13.8 & 799 \\
\hline 3 & 0.0114 & 0.229 & 14.4 & 1137 \\
\hline 4 & 0.0095 & 0.218 & 15.2 & 1238 \\
\hline 5 & 0.0083 & 0.200 & 15.1 & 1720 \\
\hline 6 & 0.0066 & 0.205 & 17.7 & 3599 \\
\hline 7 & 0.0043 & 0.235 & 26.4 & 4062 \\
\hline 8 & 0.0038 & 0.221 & 26.8 & 5728 \\
\hline 9 & 0.0030 & 0.222 & 31.7 & 6071 \\
\hline 10 & 0.0028 & 0.208 & 30.7 & 9489 \\
\hline 11 & 0.0021 & 0.213 & 37.7 & 11160 \\
\hline 12 & 0.0019 & 0.206 & 39.6 & 25299 \\
\hline 13 & 0.0012 & 0.224 & 59.1 & 36897 \\
\hline 14 & 0.0009 & 0.224 & 69.5 & - \\
\hline k average value & $0.216 \pm 0.017$ & - & \\
\hline
\end{tabular}

Calculation of the reaction rate constant according to the kinetic equation of the first order showed the values of constants fluctuating about one value with deviations within the possible error of the experiment. For kinetic equations of the second and third order, there is no constancy of the values of the velocity constant, which should not depend either on time or on the concentration of matter.

Having performed similar calculations for each of the five destructor strains, we obtained the average value of the rate constant of the CAPB biodegradation reaction by bacteria of the genus Pseudomonas, which is $0.212 \pm 0.011$ day $^{-1}$.

\subsection{Kinetic Equation of the Reaction of Biological Decomposition of Surfactant}

Therefore, we obtained the necessary data for deriving the kinetic equation of the reaction of biological decomposition of surfactant CAPB by bacteria of the genus Pseudomonas:

$$
C_{t}=C_{0} \times\left[\exp ^{\wedge}(-0.212 \times t)\right]
$$

In Equation (2), $C_{t}$ is the concentration of the surfactant at time $t ; C_{0}$ is the initial concentration of the surfactant; and $t$ is the duration of the biodegradation process. 
Using Equation (2), knowing the initial concentration of surfactants, it is possible to find the concentration of the substance in the reaction mixture at any time. This kinetic model of the process allows us to determine the time at which the surfactant concentration reaches a given value, which is important for determining the period of reduction in the surfactant concentration to the maximum permissible. These models are necessary for the selection of kinetic parameters when conducting research on the disposal of toxic organic substances by biological objects.

The process of surfactant biodegradation can be influenced by such factors as the introduction of additional easily digestible nitrogen sources, which leads to an acceleration of biodegradation [4]. Considering temperature and $\mathrm{pH}$ as factors, it is necessary to take into account the optimum temperature and $\mathrm{pH}$ [2].

In the process of studying the biodegradable characteristics of pure cultures, a number of regularities were revealed, thanks to which, it is possible to predict the future course of the process at the beginning of the experiment.

\section{Conclusions}

It was shown that concentrated solutions of the betaine surfactant cocamidopropylbetaine are toxic to bacteria of the genus Pseudomonas. The minimum inhibitory concentration of the surfactant was determined as $45.7 \mathrm{mmol} / \mathrm{dm}^{3}$. The regularities of the process of biological decomposition of surfactant were studied. It was established that the reaction obeys a first-order kinetic equation with a velocity constant of $0.212 \times 0.011 \mathrm{day}^{-1}$. Using the obtained kinetic parameters, the equation of the reaction of the biological decomposition of betaine surfactant by bacteria of the genus Pseudomonas $C_{t}=C_{0} \times\left[\exp ^{\wedge}(-0.212 \times t)\right]$ was derived.

We obtained the kinetic models that are necessary for the selection of kinetic parameters when conducting research on the disposal of toxic organic substances by biological objects. Based on the fact that the operation of some biological treatment plants in winter is carried out at low temperatures, at which the metabolic processes of bacteria slow down, in the future we plan to investigate the kinetics of the biodegradation process in a different temperature range.

Author Contributions: Conceptualization, O.V.S. and A.S.B.; methodology, all authors; formal analysis, L.S.D. and A.Y.P.; investigation, A.S.B.; resources, O.V.S. and A.S.B.; data curation, O.V.S.; writing—original draft preparation, A.S.B. and O.V.S.; writing—review and editing, O.V.S., A.S.B. and L.S.D.; visualization, A.Y.P.; project administration, A.Y.P.; funding acquisition, A.Y.P. All authors have read and agreed to the published version of the manuscript.

Funding: This research was funded by a Grant of the President of the Russian Federation for State Support of Leading Scientific Schools of the Russian Federation, grant number NSh-2694.2020.4.

Conflicts of Interest: The authors declare no conflict of interest.

\section{References}

1. Palmer, M.; Hatley, H. The role of surfactants in wastewater treatment: Impact, removal and future techniques: A critical review. Water Res. 2018, 147, 60-72. [CrossRef] [PubMed]

2. Ríos, F.; Lechuga, M.; Fernández-Serrano, M.; Fernández-Arteaga, A. Aerobic biodegradation of amphoteric amine-oxide-based surfactants: Effect of molecular structure, initial surfactant concentration and pH. Chemosphere 2017, 171, 324-331. [CrossRef] [PubMed]

3. Zhang, M.; Kang, W.; Yang, H.; Li, Z.; Li, X.; Zhou, B.; Kang, X.; Li, M.; Sarsenbekuly, B. Rheology and microstructure of zwitterionic-anionic surfactant for enhanced oil recovery. J. Mol. Liq. 2021, 116910. [CrossRef]

4. Merkova, M.; Zalesak, M.; Ringlova, E.; Julinova, M.; Ruzicka, J. Degradation of the surfactant Cocamidopropyl betaine by two bacterial strains isolated from activated sludge. Int. Biodeterior. Biodegrad. 2018, 127, 236-240. [CrossRef]

5. Zhou, Y.; Xu, S.; Zhang, L.; Liu, Y.; Xia, S. Cocamidopropyl Betaine Dosage Dependence of Short-Time Aerobic Digestion for Waste-Activated Sludge Reduction. ACS Sustain. Chem. Eng. 2019, 7, 877-884. [CrossRef]

6. Vonlanthen, S.; Brown, M.T.; Turner, A. Toxicity of the amphoteric surfactant, cocamidopropyl betaine, to the marine macroalga, Ulva lactuca. Ecotoxicology 2018, 20, 202-207. [CrossRef] 
7. Sun, X.-X.; Han, K.-N.; Choi, J.-K.; Kim, E.-K. Screening of surfactants for harmful algal blooms mitigation. Mar. Pollut. Bull. 2004, 48, 937-945. [CrossRef] [PubMed]

8. Nogales, L.M.; Jiménez, L.L.; Abarca, L.E.; Gil, M.M.; López-Nieves, M. Cocamidopropyl Betaine Surfactant 0.075\% Solution in Physiological Serum for Hygiene Process of COVID-19 Intubated Patients. Int. J. Pharm. Compd. 2020, 24, 358-364. [PubMed]

9. Burlachenko, A.S.; Salishcheva, O.V. Concentration dependence of antimicrobial properties of various surfactants against bacteria Pseudomonas putida. J. Sib. Fed. Univ. Chem. 2021, 14, 207-217. [CrossRef]

10. Sibieva, L.M.; Degtyareva, I.A.; Sirotkin, A.S.; Babynin, E.V. Composition of activated sludge microbial community used in the combined biological and chemical wastewater treatment. Proc. Univ. Appl. Chem. Biotechnol. 2019, 9, 302-312. [CrossRef]

11. Shtepa, V.; Balintova, M.; Chernysh, Y.; Chubur, V.; Demcak, S.; Gautier, M. Rationale for the Combined Use of Biological Processes and AOPs in Wastewater Treatment Tasks. Appl. Sci. 2021, 11, 7551. [CrossRef]

12. Chowdhury, S.; Rakshit, A.; Acharjee, A.; Saha, B. Biodegradability and biocompatibility: Advancements in synthetic surfactants. J. Mol. Liq. 2021, 324, 115105. [CrossRef]

13. Khalil, M.; Liu, Y. Greywater biodegradability and biological treatment technologies: A critical review. Int. Biodeterior. Biodegrad. 2021, 161, 105211. [CrossRef]

14. Fromel, T.; Knepper, T.P. Mass spectrometry as an indispensable tool for studies of biodegradation of surfactants. Trends Anal. Chem. 2008, 27, 1091-1106. [CrossRef]

15. Solyanikova, I.P.; Golovleva, L.A. Hexadecane and hexadecane-degrading bacteria: Mechanisms of interaction. Microbiology 2019, 88, 15-26. [CrossRef]

16. Meng, L.; Li, W.; Bao, M.; Sun, P. Effect of surfactants on the solubilization, sorption and biodegradation of benzo (a) pyrene by Pseudomonas aeruginosa BT-1. J. Taiwan Inst. Chem. Eng. 2019, 96, 121-130. [CrossRef]

17. Swati, P.G.; Indu, S.T. Biodegradation of pyrene by Pseudomonas sp. ISTPY2 isolated from landfill soil: Process optimisation using Box-Behnken design model. Bioresour. Technol. Rep. 2019, 8, 100329. [CrossRef]

18. Korshunova, T.Y.; Kuzina, E.V.; Rafikova, G.F.; Loginov, O.N. Using pseudomonas for cleaning the environment from oil contamination. Eco. Biotech. 2020, 3, 18-32. [CrossRef]

19. Korotneva, I.S.; Dmitriev, K.E.; Mukhin, A.S. Biodegradable polymer composites materials based on synthetic polymers and natural components. Chem. Towards Technol. Step-By-Step 2020, 1, 81-89. [CrossRef]

20. Kokhanchik, Y.A. Influence of sulfate-reducing bacteria on the objects of the oil and gas complex and methods of inactivation their vitality. Environ. Prot. Oil Gas. Complex. 2019, 2, 34-39. [CrossRef]

21. Edrisov, A.T.; Aitbekova, D.E.; Tusipkhan, A.; Tateeva, A.B.; Baikenova, G.G.; Baikenov, M.I.; Kaikenov, D.A. Determination of thermokinetic parameters of high-viscosity oil decomposition in the presence of a nanocatalyst, catalytic additives and polymers by the results of thermogravimetry. Neftekhimiya 2021, 61, 319-327. [CrossRef]

22. Dyshlyuk, L.S.; Prosekov, A.Y.; Asyakina, L.K. Property study of natural polysaccharide biodegradable films. Proceedings of Universities. Appl. Chem. Biotechnol. 2019, 9, 703-711. [CrossRef]

23. Gholami, A.; Golestaneh, M.; Andalib, Z. A new method for determination of cocamidopropyl betaine synthesized from coconut oil through spectral shift of Eriochrome Black, T. Spectrochim. Acta-Part. A: Mol. Biomol. Spectrosc. 2018, 192, 122-127. [CrossRef]

24. Baranova, A.A.; Selyaninov, A.A.; Vikhareva, E.V. Kinetic modelling of the biomechanical processes. PNRPU Mech. Bull. 2012, 3, 6-24.

25. Ivshina, I.B.; Tyumina, E.A.; Bazhutin, G.A.; Selyaninov, A.A.; Vikhareva, E.V. Mechanisms of bacterial conversion and degradation of pharma pollutants from nonsteroidal anti-inflammatory drugs. Perm Fed. Res. Cent. J. 2020, 3, 6-22. [CrossRef] 